\title{
LA REPRESENTACIÓN DE LA MUJER EN LA NARRATIVA ARGENTINA DE FIN DE SIGLO XIX. UNA ETIOLOGÍA IMAGINARIA DEL CUERPO Y LA MORAL FEMENINA*
}

Fecha de recepción: 25 de marzo de 2014 Fecha de aprobación: 11 de abril de 2014

\section{Resumen}

De nuestro corpus de análisis se podría inferir que en un ámbito social dominado por el hombre, la autonomía del género femenino, lejos de reivindicarse, era representada como locura, histeria o neurosis, estados mentales que se consideraban patologías frecuentes de la mujer "debido a su predisposición natural”. A fines del siglo XIX, los profesionales relacionados con las ciencias médicas se habían convertido en fiscalizadores sociales que decodificaban y controlaban el lenguaje de los cuerpos. Determinaban la posibilidad de su captura para el sistema y sus redes de dominio y evaluaban su factibilidad de inserción en la modernidad socio-económica. Los escritores no escaparon a la concepción conservadora sobre el repertorio moral que definía la conducta de las "irresponsables". La literatura ofició como mediación al servicio de los intereses dominantes, como respuesta simbólica a la progresiva modificación del lugar social que comenzaron a ocupar las mujeres en la cultura del Río de la Plata.

Palabras clave: Narrativa argentina de fin de siglo XIX, autonomía de la mujer, positivismo, liberalismo económico.

* Este artículo se inscribe en la investigación del Proyecto11/H334, Discursos y representaciones literarias en los textos de los escritores de la coalición del '80, sus opositores y excluidos, ideas-imágenes y derivaciones históricas.

Citar: Delllarciprete, R. (julio - diciembre de 2014). La representación de la mujer en la narrativa argentina de fin de siglo XIX. Una etiología. 93-103.

\section{Rubén Dellarciprete}

Universidad Nacional de

La Plata, Argentina

rdellarciprete13@gmail.com

Doctor en Letras. Profesor Instituto de Investigaciones en Humanidades y Ciencias Sociales, Centro de Literatura y Literaturas Comparadas Facultad de Humanidades y Ciencias de la Educación, Universidad Nacional de La Plata. 
WOMAN'S REPRESENTATION IN THE ANGERTINIAN NARRATIVE AT THE END OF THE XIX CENTURY. AN IMAGINING STUDY ABOUT THE BODY AND THE FEMALE MORAL

\section{Abstract}

From our corpus of analysis it could be inferred that in a social field dominated by men, the autonomy of the female gender, far from be claimed, it was represented as madness, hysteria or neurosis, mental states that were considered common pathologies of the woman "due to her natural predisposition". At the end of 19th century, the professionals involved in the medical sciences had become supervising social that they decoded/deciphered and controlled the language of bodies. They determined the possibility of their capture system and their network of domain and assessed their feasibility for inclusion in socio-economic modernity. The writers did not escape to the conservative conception of the moral code that defined the "irresponsible" behaviour. Literature officiated as mediation in the service of the dominant interests, as a symbolic response to the progressive modification of the social place that women began to occupy in the culture of the Río de la Plata.

Keywords: Argentina narrative of late 19th century, autonomy of women, positivism, economic liberalism.

\section{LA REPRÉSENTATION DE LA FEMME DANS LA NARRATIVE ARGENTINE DE LA FIN DU XIX ÈME SIÈCLE. UNE ÉTIOLOGIE IMAGINAIRE DU CORPS ET DE LA MORALE ARGENTINE.}

\section{Résumé}

De notre corpus d'analyse, on pourrait inférer que, dans un milieu social dominé par l'homme, l'autonomie du genre féminin, loin d'être revendiquée, était représentait comme folie, hystérie ou névrose, des états mentaux qui étaient considérés des pathologies fréquentes chez la femme «dû à sa prédisposition naturelle ». À la fin du XIXème siècle, les professionnels liés aux sciences médicales, étaient devenus des fiscaux sociaux qui décodaient et contrôlaient le langage des corps. Ils déterminaient la possibilité de leur capture pour le système et leurs réseaux de domination, et ils évaluaient leur possibilité d'insertion dans la modernité socio-économique. Les écrivains n'ont pas échappé à la conception conservatrice sur le répertoire moral qui définissait la conduite des «irresponsabilités ». La littérature a eu le rôle de médiatrice au service des intérêts dominants, en réponde symbolique à la progressive modification du lieu social que les femmes ont commencé à avoir, dans la culture du Rio de la Plata.

Mots clés: Narrative argentine de la fin du XIXème siècle, autonomie de la femme, positivisme, libéralisme économique 


\section{Condición de clase, derechos de género}

El presente trabajo toma como corpus de estudio algunos textos narrativos, novelas y nouvells que no presentan a la mujer como protagonista, pero su lateralidad, justamente, nos posibilita la reconstrucción del lugar que ocupaba en la cultura argentina de fines del siglo XIX. Dos de los autores estudiados, Lucio V. López y Eduardo L. Holmberg, pertenecían a la clase patricia; provenían de familias que habían participado de la gesta revolucionaria y fundacional. El abuelo de Lucio V. López, Vicente López y Planes, fue el creador del Himno Nacional Argentino y el abuelo de Eduardo Holmberg, Eduardo Kannitz, Barón de Holmberg, participó de los Ejércitos del Norte y las luchas por la Independencia. El tercer autor, Antonio Podestá, pertenecía, junto con otro médico y novelista, Francisco Sicardi, a los inmigrantes de primera generación de origen italiano. Tanto Podestá como Sicardi, desligados de la tradición e incluso cuestionados por la elite, consideraron a la literatura como un medio para conquistar el reconocimiento social. Antonio Argerich, médico y novelista de origen patricio, uno de los más renuentes en aceptarlos, temía que a pesar de su formación profesional y de su condición de hombres cultos, siguiendo los dictados de la herencia, sufrieran una regresión a los estadios primitivos del hombre. Más allá de estos conatos discriminatorios, Podestá y Sicardi se hicieron un lugar expectante dentro de la medicina y también de la literatura. Sus novelas formalmente naturalistas, aunque descentradas del punto de vista que proponía el modelo francés, no cuestionaron sino que funcionaron como agentes reproductores del imaginario dominante.

El costumbrismo de Lucio V. López, el naturalismo de Antonio Podestá y el neodecadentismo asociado con los procedimientos del género policial clásico de Eduardo Holmberg nos permiten trazar una semblanza de época y advertir tanto la creciente autonomía de la mujer en la cultura de fin de siglo como la concepción restrictiva y conservadora con que el hombre la evaluaba a través de sus obras de ficción. El proyecto progresista de la coalición de los ochenta, que encontró su continuidad en los años noventa, consideraba que la literatura no dejaba de promover la comprensión del mundo y el individuo y por lo tanto resultaba (a la vez que constructo ideológico rigurosamente conceptualizado y de genuina intensidad filosófica) un recurso indispensable al momento de dirimir en el campo simbólico la gesta re-fundacional (Jameson, 2002, pp. 121-176).

Los nuevos tiempos traían transformaciones esperanzadoras pero también efectos colaterales no deseados que fueron combatidos de diversas maneras. El proyecto de Ley de Extranjeros, que Estanislao Zeballos presentó en el Congreso Nacional en 1883 (nunca aprobado por dilaciones facciosas), la Ley de Residencia (exigida por la Unión Industrial Argentina e impulsada en 1899 por Miguel Cané con el propósito de obtener la facultad de expulsar extranjeros sin juicio previo) así como las regulaciones higienistas-moralistas que intentaban intervenir las conductas de la ciudadanía (promovidas por el Doctor Guillermo Rawson) resultaron algunas de las disposiciones institucionales que se ensayaron con el fin de contener los desbordes no esperados de la modernidad (Rawson, 1928, p. 65-150). En este contexto, la literatura actuó como catalizadora de los intereses de la elite y ofició de soporte a las construcciones del "otro" como antagonista, imaginario en el cual se vio representado el inmigrante y, en más de una oportunidad, la mujer.

El positivismo argentino no alcanzó a diferenciar (si lo hizo prevaleció la condición de 
clase y el instinto conservador) entre lo diferente y la locura patológica, entre la transformación de valores y la insensatez moral. Lo "extraño" se tornó motivo de estudio criminológico, digno de la censura social, de la pena judicial o de la eliminación. Una hermenéutica filosófica de la modernidad pondría en evidencia que los personajes femeninos de las ficciones de los años ochenta y noventa, abismados en supuestos extravíos condenables, resultaron blancos de prejuicios ideológicos, intereses mezquinos e imaginería obtusa. El pensamiento neo-científico dominante posibilitaba por entonces la categorización de los comportamientos en una trama biologicista psicopática que justificaba las censuras simbólicas y la regulación institucional de las conductas (Bertoni, 2007, pp. 17-147).

Cuando la autonomía y las transgresiones femeninas atentan contra la "histología socioeconómica"1
La lectura sobre la década del sesenta del siglo XIX que realiza Lucio V. López en La gran aldea (1884), se fundamenta en diversidad de motivos, algunos relacionados con el proceso histórico que por entonces vivía el país; otros responden a preocupaciones de índole personal ${ }^{2}$. El cronista Julio Rolaz, narrador de la novela, es un intérprete de la historia reciente. Durante la primera parte del trayecto narrativo regresa al pasado para saldar cuentas con el mitrismo; durante la segunda parte elabora el relato sobre el disgusto nacional, combinación de indolencia liberal e interferencia de los advenedizos en el Poder. La representación discursivoliteraria toma múltiples formas: la descripción irónica, la reproducción en discurso directo de las psicologías e ideologías imperantes y la narración en primera persona. El punto crucial de la historia o las historias contadas se encuentra en el lugar de la enunciación.
Si consideramos que se trata de una ficción autobiográfica, como sostiene la mayoría de los críticos, podríamos asociar narrador y autor sin ripios formales graves (Ludmer, 1999, pp. 45-54). Según expone David Viñas en Literatura argentina y política (Viñas, 2005, p. 68), el protagonista observa y cuenta escondido "debajo de la mesa del comedor", donde además acostumbraba a leer de niño; este lugar simbólico da espesor al narrador. También mira desde un "palco-balcón", donde se desvanece su sensación de "inseguridad y caída", y acopia conciencia sobre la realidad que lo rodea. El abajo y el arriba como referentes espaciales abren un pan-óptico.

El regreso al pasado le permite a Lucio V. López, a través de su alter ego, Julio Rolaz, desquitarse de la humillación sufrida por su padre Vicente Fidel López, durante las jornadas de junio de 1852 en las que defendió el pacto de

1 Parafraseamos la expresión "histología histórica", que tomamos de La neurosis de los hombres célebres en la historia argentina de José Ramos Mejía. Ramos Mejía inspirado en autores como Thomas Macaulay aplicaba a la trama histórica definiciones propias de las ciencias naturales (Ramos Mejía, 2013, pp. 162).

2 Si bien, por las condiciones que impone el presente artículo, priorizamos la investigación sobre la representación de la mujer, Lucio V. López, en La gran aldea, realiza una pormenorizada lectura crítica sobre las transformaciones que experimenta el casco urbano de la ciudad de Buenos Aires. Fernando Aliata considera que López, más allá de confinar el pasado a una imagen estática, cristalizada, también transmite el comienzo del cambio que la ciudad de Buenos Aires está viviendo. Se sitúa en el borde de la ciudad anterior y la que está naciendo, desde donde observa los desplazamientos, reemplazos y migraciones (Aliata, 1992, p. 55). En el fin de siglo, se modificaron por completo las representaciones de lo que había sido la ciudad. Las redes de sentido que comunicaban a sus habitantes se habían reconfigurado, pero de ningún modo se había instalado una fragmentación o atomización espacial que desconectara a los distintos grupos sociales. A pesar de que los integrantes de la élite tradicional y los nuevos ricos se habían ido desplazando progresivamente hacia el norte del mapa urbano, dejando el centro y especialmente el sur a las comunidades de inmigrantes, la esterilización no fue total. La necesidad de mano de obra a bajo costo, la ocupación de terrenos vacíos por indeseados (todavía la expansión metropolitana, si bien se perfilaba clasista, era irregular), mantenía abiertos los vasos comunicantes que resultaban transmisores de contagios estéticos, lingüísticos y, los más inmediatos y preocupantes, virales. 
San Nicolás y fue vencido por Mitre y la política porteña. Los representantes del mitrismo van a ser caricaturizados por medio de trazos hiperbólicos con la inocultable intención de desvalorizarlos. La tía Medea aparece siempre focalizada por la lente del narrador. Las secuencias narrativas que dan vida al personaje configuran un modo de existencia que describe de manera despectiva a la tía en su moralina, punto de vista que Rolaz repite en la segunda parte de la novela, en la Buenos Aires de principios de los años ochenta, cuando intenta dar cuenta del comportamiento de los "otros", los arribistas, los inmigrantes. Es decir, desde un comienzo, el otro y la mujer se muestran íntimamente vinculados por la utilización de recursos formales de valores negativos. Con un grado de sutileza que el grotesco no permite avizorar en Medea, Rolaz ironiza sobre el lugar que pasaron a ocupar, social, político y económico, los rastacueros como los Montefiori. No se puede discutir el corte y la alteración significante que implica la división en dos etapas de la novela, pero ciertos motivos mantienen la unidad moral o de conciencia de Julio Rolaz. Su tendencia misógina es uno de ellos:

“¿Entiende usted, Misia Medea?- agregó dirigiéndose en voz baja a mi tía.

- No señor don Higinio; pero yo también lo encuentro admirable como usted."

(López, 1928, p. 24)

El desprestigio individual de Medea se lo puede justificar por los antecedentes que el personaje acredita en la historia, pero si uno lo expone comparativamente con el trato que reciben en general los personajes femeninos, podría concluir que está dirigido a la mujer y no se limita exclusivamente a su tía. Josefina Ludmer, en El cuerpo del delito, advierte la actitud misógina del narrador aunque la confina a una aversión contra las cazafortunas (una actitud frecuente en las mujeres de la época, según López, que privilegiaban maridos con buena posición económica por encima del amor, mandato del cual no escapan Valentina, la que fuera primera novia de Julio Rolaz, ni Blanca Montefiori), y contra las indignas habitúes del Colón, institución que, como el Covent Garden de Cané, debiera producir una purificación natural de clase y además de género. Según Lud- mer, la misoginia de La gran aldea comienza en la cazuela del gran teatro pero no culmina en ella (Ludmer, 1999, p. 68). El siguiente pasaje ejemplifica "la solución final” (Ludmer, 1999, p. 69) que proponen López y el autoritarismo de los patricios. "Los que tenéis autoridad, abolid la cazuela, meted en ella el elemento masculino; la mujer sola se vuelve culebra en aquel antro aéreo"' (López, 1928, p. 119).

Tres problemas, que reclaman rápida solución, se presentan a los ojos de López: la visibilidad social de mujeres que no registran una pertenencia de clase acreditada por la tradición, su progresiva autonomía que les permite ocupar espacios fuera del alcance de la fiscalización masculina, y la imposibilidad del género femenino de apreciar la singularidad de una obra estética, facultad exclusiva del hombre culto $^{3}$.

A esta altura, no se puede pasar por alto el enfrentamiento hombre / mujer que según Gabriela Nouzeilles en su artículo titulado "Políticas médicas de la histeria: mujeres, salud y representación en

3 Algunos críticos sugieren que López, afecta sencillismo para diferenciarse de los nuevos ricos, pero López abomina de la práctica deformante que hacen del arte los insurgentes, provenientes de la inmigración, o de los estancieros incultos, criticados por sus ostentosos mausoleos mamarrachescos si se los cotejaba con los de los próceres. Un acto de voluntad supremo puede interpretar como sencillismo la actitud del autor de La gran aldea frente a la ecléctica Buenos Aires. Basta con leer sus textos titulados "El teatro inglés" y "La comedia francesa", publicados primero en el periódico El nacional (1880) y luego como capítulos en Recuerdos de viaje (1880), para alejar cualquier duda al respecto. Los mismos son una declaración o un manifiesto sobre su vocación por la alta cultura (López, 1915, p. 170-193). 
el Buenos Aires del fin de siglo", atravesaba la sociedad de la época. La autora argumenta que la fuerza desarrollista de los primeros intentos modernizadores en Latinoamérica supuso la expulsión de la comunidad deseada de todo aquello que el ojo aristocráticoburgués percibía como distinto de sí. Nouzeilles afirma que la literatura se había convertido en un espacio prolífico como generador de respuestas a la parcial modificación del lugar social de las mujeres que había comenzado a insinuarse en los principios modernizadores (Nouzeilles, 1999, p. 25).

En La gran aldea, la mujer en general, sobre todo las que ocupan un rol significativo en la segunda parte, resulta un núcleo irradiador de fuerzas desequilibrantes para la mentalidad burguesa. La clave representativa de este corte genérico se produce cuando Julio Rolaz resiste la pulsión erótica y mantiene su integridad moral frente a la propuesta amorosa de Blanca Montefiori casada con su tío. El sujeto transgresor o "criminalizado" por su conducta, si seguimos la línea de pensamiento de Nouzilles, podría estar representado por Blanca.

Para los hombres de letras, en este caso particular Lucio V. López, insigne representante de la clase patricia, la imagen de la mujer de fin de siglo no supo- nía una defensora de la nación, o lo que era igual, de los intereses políticos de la tradición que ejercía el control del poder. Si bien en la primera mitad del siglo XIX, se había utilizado la figura de la mujer como un ejemplo de los valores superiores que le daba sustento al proyecto liberal, sobre las estribaciones del cambio de época, la presencia femenina pasó a simbolizar una amenaza. Mientras más progresaba su autodeterminación más se la desplazaba hacia un lugar de conflicto e interferencia del normal desarrollo de las cuestiones culturales, políticas, económicas, morales y psicológicas.

Antonio Podestá, en su novela Irresponsable (1889), tematiza, a través de sus dos personajes centrales, la problemática del sujeto que no responde a las condiciones impuestas por la modernidad capitalista. El itinerario espacial que traza el relato recorre distintos ámbitos de Buenos Aires pero se unifica significativamente en el mundo de la medicina, disciplina que practicaba su autor.

El estudio anatómico del cadáver de una bella mujer de clase baja motiva al narrador, estudiante de medicina, a reflexionar sobre las relaciones entre la belleza y la virtud; concluye, como Shakespeare en Hamlet, que siempre se impone la belleza y con ella la perversión moral. El protagonista masculino, pareja de la joven, conocido solamente por su sobrenombre, "el hombre de los imanes", termina de proporcionarle al estudiante la información necesaria sobre el estado psíquico emocional de su compañera y de este modo el narrador consigue cerrar el diagnóstico: la compulsión por las pasiones bajas, síndrome genérico, dominaban su voluntad.

Cuando desesperado "el hombre de los imanes" había consultado, en una oportunidad anterior, a un especialista, la respuesta no había dejado lugar a dudas: era natural que fuera perversa, degradada, porque su organismo estaba determinado de esa manera. El profesional había definido epistemológicamente como histeria el cuadro clínico que presentaba la mujer, fijando así la etiología de su comportamiento y había disuadido a su consultor de la imposibilidad de volver a capturar ese cuerpo, que por otra parte se perdería también para el sistema y sus redes de dominio.

A finales de siglo XIX, la metodología interpretativa de la medicina hegemonizó las tecnologías de detección de lo diferente y subversivo, entendido como patología. El narrador de Irresponsable representa a un observador invisible que decodifica y controla el lenguaje de los cuerpos; registra y comuni- 
ca además, los riesgos que implica su equívoca inserción para la modernidad socio-económica. La prostitución primero y finalmente el suicidio cerrarían el ciclo de vida del personaje femenino, una inepta en términos morales que no pudo romper el cerco determinista y, por lo tanto, no tendría posibilidades de responder a las exigencias de la coyuntura socio-histórica.

Un segundo ejemplo de sujeto que atenta contra el orden y las buenas costumbres, es el caso de "el hombre de los imanes". Este personaje presenta, al igual que su compañera, un comportamiento fronterizo, que los higienistas de la época consideraban inestabilidad nerviosa, concepto que se origina literariamente en Poe pero que recorre gran parte del siglo $\mathrm{XIX}^{4}$. El hombre moderno vive en un estado de desequilibrio continuo que le produce una alteración nerviosa. En algunos casos, lo vuelve irrecuperable (Colette, 2004, pp. 25-36). El protagonista de la novela preocupa a su narrador, pero no tan sólo como un cuadro clínico, sino como modelo descriptivo de disfuncionalidad social. Esto explicaría el modo en que se articularía la ficción, desde una perspectiva médica, con la producción simbólica y cultural que responde al proyecto científico positivista y a los estamentos de control. Las cabezas delirantes de estos seres envilecidos y degradados, capaces de cualquier monstruosidad tienen como "amparo el manicomio o la cárcel para que la sociedad pueda vivir tranquila, sin codearse con el peligro y sin escuchar el dolor" (Podestá, 1954, p. 219).

En el siglo XIX, la práctica de la penitencia religiosa fue complementada con actividades como la medicina, la psiquiatría, la psicología y la pedagogía. Con el desarrollo de cada una de estas disciplinas se anexó la conducta irregular a la enfermedad mental y se caracterizó cada uno de los posibles desvíos. En el centro de esta operación social de control, se levantó la figura del médico reemplazando al sacerdote, quien hasta allí había sido el único administrador de la moral (Foucault, 1990, p. 45). En la novela de Podestá, el hospicio es un espacio que sintetiza el proceso que hasta el momento venimos describiendo. Es en primera instancia un viejo convento de los padres Belermitas que se reconvierte en sede del sistema médico alienista moderno, donde se estudian y mantienen cautivos a quienes representan una amenaza social y además es un monumento tradicional que conserva viva la memoria sobre la reconquista de Buenos Aires de manos de los ingleses. El edificio se transforma así en un emblema de la fusión que en los últimos años del siglo se produce entre la tradición patrística y la modernidad.

Pocos años después que Podestá escribiera su novela, la revista socialista La montaña, dirigida por José Ingenieros y Leopoldo Lugones, entabló una fuerte polémica con el intendente de la ciudad de Buenos Aires, Francisco Alcobendas (Ingenieros-Lugones, 1996, pp. 125-157). El motivo de la disputa fue el negocio de la prostitución en las calles de la ciudad. El enfoque no varió demasiado del "estudio literario" realizado por el escritor de Irresponsable. La cuestión moral y de género carga con todo el peso de la discusión pública. Para curiosidad del

4 "El hombre de los imanes" vivía en un barrio marginal de la ciudad de Buenos Aires. Las novelas de Zola habían ejercido una influencia negativa en su conducta. Su cabeza estaba llena de escenas de L'Assommoir, donde "una sociedad de obreros viciosos desfilaba ante sus ojos"; el grado de sus vicios estaba proporcionalmente relacionado con la escasez de sus recursos; los carbones de la mina destruían sus pulmones y todo a cambio de un salario que no cubría sus primeras necesidades. El imaginario zoliano corrompió la mentalidad de muchos incautos que confundieron Europa con Buenos Aires. Los textos del autor francés son representativos de la miseria de allá, no de la prosperidad argentina. Aquí la riqueza está al alcance de quien se lo proponga, sostiene Antonio Podestá (Podestá, 1954, 217). El intento de desautorizar a Zola y señalarlo como corruptor de conciencias forma parte del trabajo de descentramiento del modelo naturalista francés que llevaron a la práctica nuestros escritores (Olivera, 1887, p. 125). 
lector, la problemática social que condicionaba la vida de estas "chinitas", como las había definido Podestá, no fue tenida en cuenta por los jóvenes socialistas cuando analizaron el cuadro de situación ciudadano. La intelectualidad, en sus distintos pliegues, no escapó a los alcances de la concepción oficial sobre el conservador repertorio de valores que definía la conducta de los "irresponsables". La ecuación rédito económico-comportamiento ético movilizaba a unos y otros cuando se interponía la discusión sobre el proyecto modernizador de la burguesía.

En la nouvelle La bolsa de buesos (1896) de Eduardo Ladislao Holmberg, el mundo razonado y controlado de la ciencia se opone al de la belleza, asociado a lo femenino. Surge entonces la antítesis entre lo racional y lo irracional, que a medida que avanza la investigación policial se multiplica en distintas categorías: bien / mal, justicia / injusticia, cordura / locura, detective / criminal, hombre / mujer. La estructura profunda del texto responde a un sistema binario de organización de los materiales que se multiplica en los distintos planos del relato: dos son los crímenes iniciales, dos son los esqueletos, dos son los investigadores. Este sistema binario que traslada sentido hacia todos los niveles del tex- to, alcanza su cima con el recurso que permitió mantener el misterio a lo largo de toda la novela: la doble personalidad de la asesina: Clara / Antonio. Eduardo Holmberg textualiza el incipiente enfrentamiento entre el poder conservador controlado por el hombre y la irrupción del nuevo rol social representado por la mujer. Clara confronta con el orden establecido, pero para eludir los condicionamientos del sistema, adopta el travestismo. La construcción del personaje, pone en discusión, a través de una estética decadente, la supuesta condición histérica de una mujer que trasgrede las mediatizaciones y las restricciones que provienen de la axiología burguesa.

Gabriela Nouzeilles, en el trabajo citado con anterioridad, considera que la fantasía policial subrayada por el texto de Holmberg forma parte de la reacción masculina contra la liberación de la mujer. Si tomamos como referencia válida la tesis de Nouzilles, encontramos que el relato adquiere la fisonomía de una lucha que trasciende las circunstancias que rodean la relación procedimental entre detective y criminal, para trasladarse del campo literario hacia un problema entre géneros sexuales.

Por otra parte, el grado de peligrosidad que la percepción masculina le atribuye al rol adquirido por la mujer en nuestra sociedad de fin de siglo, queda reflejado en la interpretación que hace al respecto Néstor Ponce en su artículo "Holmberg: de vagos, mujeres y criminales." Dice Ponce: "Como todo asesino serial que se respete, Clara procede a firmar su crimen, amputando la costilla izquierda [...] Resulta difícil no ver en este gesto un símbolo de la castración." (Ponce, 1998, p. 124).

La imagen de la castración remite a la emergencia de una amenaza que pone en riesgo el dominio del hombre. El espacio recuperado en la discusión pública por el mal considerado sexo débil, se ve representado en el accionar de Clara, no como una reivindicación necesaria por los agravios sufridos sino como resultado de su histeria, estado mental que se adjudicaba como patología frecuente al sexo femenino.

La bolsa de huesos no se limita a repetir de manera mecánica las estrategias discursivas que impone un género literario determinado, sino que hace de la narración un territorio productivo donde se pueden representar los cruces y posicionamientos que tienen lugar en el campo social. El narrador científico de Holmberg trabaja, con su relato, como el naturalista que dispone $y$ 
reconstruye sobre su mesa de estudio las reliquias arqueológicas. En la medida en que intenta reconfigurar el objeto o el cuerpo original, va descubriendo la silueta difusa de lo monstruoso y lo aberrante. Clara resulta una devoradora de hombres. Encubierta por la arquitectura de sus crímenes, por la aparente racionalidad de sus actos, se expande una fuerza primigenia, ancestral, que pone en peligro la estabilidad alcanzada durante los últimos años. Holmberg se ve obligado a romper las leyes del género policial porque lo exige la necesidad pedagógica de frustrar la compulsión femenina. El científico y detective aficionado, después de haber procedido según el manual escrito por Edgard Allan Poe y Connan Doyle, no entrega la información a la policía para que se produzca la detención de la criminal y se la juzgue. Convence a Clara de que se suicide. Esa compulsión castradora no merece ni siquiera ocupar el espacio de una cárcel o reformatorio, lugares donde terminaban los personajes de Antonio Podestá. Contra la sugerencia del círculo de lectores más íntimo, Holmberg se resiste a cambiar el final. La nouvelle se impone, por sobre los procedimientos policiales y la estética decadente, como un relato instructivo sobre los saberes del cuerpo y la experiencia secular femenina.

\section{Una nueva voz en el proyecto nacional}

De nuestra investigación se podría inferir, entonces, que el determinismo vigente intentaba coartar cualquier iniciativa que produjera una lectura alternativa a la versión oficial. Los escritores emergentes de la elite o consecuentes con la misma, pertenecían a un estatus social y cumplían una función institucional. No eran representantes de la bohème. Eran intelectuales orgánicos. Sus obras resultan de sencilla clasificación independientemente de sus valores artísticos. No se resisten a las categorías genéricas a pesar del eclecticismo que practican Lucio V. López y Eduardo L. Holmberg o el descentramiento de Antonio Podestá. La falta de experimentación con la escritura es una elección estética relacionada con la necesidad de cerrar los diversos frentes que surgían por fuera del statu quo. Se intentaba contener por la forma, a riesgo de cristalizar la condición dinámica del progresismo que defendían.

La frontera entre lo público y lo privado, entre la familia y el estado, guardada en otros tiempos por la maternidad republicana (Kerber, 1997, p. 48), a través de la cual las mujeres ejercían su función patriótica dentro del hogar, había comenzado a filtrar, de manera irrenunciable, la liberación del cuerpo femenino de los controles para estatales como el marido, la medicina y la literatura. La sexualidad y la voz de la mujer comenzaron a trascender desde lo privado hacia el dominio de lo público. El esfuerzo de Lucio V. López y con él la mayoría de los escritores de la elite, de Antonio Podestá y los arribistas con intenciones de pertenecer, de Eduardo L. Holmberg y los modernistas neoconservadores, por preservar al género femenino de las enfermedades físicas, psicológicas, morales, y mantenerlo bajo el saludable control que significaba el reducto de la familia fue desvirtuado por el movimiento que ellos alentaban y defendían, la modernidad. La voz y la pulsión de la mujer tanto por su negación como por su inserción, no ya interferencia, abrieron una grieta en los designios de aquellos que ejercían el poder. En la modernidad periférica argentina de fines de siglo, la mujer gestiona su autonomía con singular éxito, proceso por el cual le adjudican la responsabilidad de obstruir el desenvolvimiento normal de la conciliación burguesa y el desequilibrio del orden familiar. De algún modo, lo femenino ponía en crisis y en riesgo las categorías del pensamiento heredado que pretendía por otra parte eternizarse sin hacer concesiones ni de clase ni 
de género. Como ya señalamos con anterioridad, la mujer había dejado de ser un agente mediador frente a la barbarie (desligada del lastre simbólico y el condicionante práctico que significaba el dominio exclusivo del hogar) para comenzar a disciplinar al bloque masculino dominante que se prestaba solo al liberalismo económico, ya no al político ni a las discusiones sobre los derechos civiles de "lo extraño".
El cuerpo femenino en las ficciones del fin de siglo comporta un objeto esquivo que deviene en etiología imaginaria con el solo propósito de capturarlo y sacarlo de la circulación pública. La intención es que los lectores reflexionen sobre las causas y sobre los efectos que la ruptura de las convenciones podría llegar a producir. Si se piensa que el Código Civil, redactado por Vélez Sársfield, daba a las mujeres los mismos derechos que a los menores de edad, a los locos y a los idiotas, se puede acordar, sin temor a equivocarse, que en la sociedad de fin de siglo XIX la mujer, en ciertas circunstancias, pasó a ocupar el lugar del otro, del irresponsable que ponía en cuestión la racionalidad burguesa-capitalista y el mandato masculino.

\section{Referencias}

Aliata, Fernando (1992). "Ciudad o aldea. La construcción de la historia urbana del Buenos Aires anterior a Caseros”, Entrepasados, Revista de Historia, 3: 51-65.

Bertoni, Lilia Ana (2007), Patriotas, cosmopolitas y nacionalistas. La construcción de la nacionalidad argentina a fines del siglo XIX, Buenos Aires, Fondo de Cultura Económica.

Colette, Soler (2004), El inconsciente a cielo abierto, Buenos Aires, JVE-Ediciones.

Foucault, Michel (1990), Historia de la sexualidad. La voluntad de saber, Buenos Aires, Siglo XXI.

Holmberg, Eduardo Ladislao (1957), "La bolsa de huesos", Cuentos fantásticos, Buenos Aires, Librería Hachette S. A.

Ingenieros, José y Lugones, Leopoldo (1996), La montaña, Quilmes, Universidad Nacional de Quilmes.

Jameson, Fredric (2002), Una modernidad singular, Buenos Aires, Gedisa Editorial.

Kerber, Linda, citado por Masiello, Francine (1997), Entre civilización y barbarie. Mujeres, nación y cultura literaria en la Argentina moderna, Rosario, Beatriz Viterbo Editora.

López, Lucio V (1928), La gran aldea, Buenos Aires, El Ateneo.

López, Lucio V. (1915), Recuerdos de viaje, Buenos Aires, La Cultura Argentina.

Ludmer, Josefina (1999). El cuerpo del delito. Un manual, Buenos Aires, Libros Perfil.

Nouzeilles, Gabriela (1999), "Políticas médicas de la histeria: mujeres, salud y representación en el Buenos Aires del fin de siglo", Mora, Revista del Instituto Interdisciplinario de Estudios de Género, 5: 21-38. 
Olivera, Carlos (1887), En la brecha, Buenos Aires, F. Laujaune Editor.

Podestá, Manuel (1954), Irresponsable, Buenos Aires, Biblioteca de la Nación.

Ponce, Néstor (1998). "Holmberg: de vagos, mujeres y criminales”, Cuadernos Angers, 2, 2:115-128.

Ramos Mejía, José María (2013), Las neurosis de los hombre célebres en la historia argentina, Buenos Aires, Ediciones Biblioteca Nacional.

Rawson, Guillermo (1928), Escritos Cientificos, Buenos Aires, El Ateneo. 